\title{
Titration of amlodipine to higher doses: a comparison of Asian and Western experience
}

\author{
This article was published in the following Dove Press journal: \\ Vascular Health and Risk Management \\ 4 November 2013 \\ Number of times this article has been viewed
}

\author{
Kazuomi Kario' \\ Jeffery Robbins ${ }^{2}$ \\ Barrett W Jeffers ${ }^{2}$ \\ 'Division of Cardiovascular Medicine, \\ Jichi Medical University, Shimotsuke,

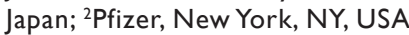

\begin{abstract}
In this retrospective analysis, data pooled from two Phase III/IV open-label Asian studies were used to quantify the additional blood pressure efficacy achieved when titrating amlodipine from $5 \mathrm{mg}$ to $10 \mathrm{mg}$ in mild/moderate hypertensive patients, and compared to data pooled from three Western studies. The primary efficacy end point was the change from baseline in sitting systolic blood pressure (SBP) and diastolic blood pressure (DBP) to the specified time point (4-8 weeks, depending on the trial). For the Asian analysis ( $n=174)$, both mean SBP and DBP were significantly decreased at the final visit (SBP $-13.3 \mathrm{mmHg}, 95 \%$ confidence interval [CI] -15.5 to -11.0 ; DBP $-9.2 \mathrm{mmHg}, 95 \% \mathrm{CI}-10.6$ to -7.8 ; both $P<0.0001)$. These results were similar to the Western analysis $(\mathrm{n}=369$; $\mathrm{SBP}-11.5 \mathrm{mmHg}, 95 \% \mathrm{CI}-13.1$ to -10.0 ; DBP $-6.3,95 \% \mathrm{CI}-7.1$ to -5.5 ; both $P<0.0001)$. In summary, titration of amlodipine from $5 \mathrm{mg}$ to $10 \mathrm{mg}$ significantly decreased both SBP and DBP in Asian patients with mild-tomoderate hypertension.
\end{abstract}

Keywords: amlodipine, hypertension, Asia

\section{Introduction}

Hypertension increases the risk of vascular disease, including stroke, myocardial infarction, nephropathy, and retinopathy, ${ }^{1-3}$ and is a highly prevalent and modifiable risk factor for cardiovascular disease in both economically developed and developing countries. Even small changes in blood pressure have been shown to lower the risk of stroke (by 35\%-50\%), myocardial infarction (by $20 \%-25 \%$ ), and heart failure (by $>50 \%$ ). ${ }^{1,4-7}$ However, pharmacological intervention is usually required to achieve this.

Calcium-channel blockers (CCBs), including amlodipine, are an effective treatment option for hypertension, as their efficacy is affected neither by age nor ethnicity and because both the risks of cardiovascular events and all-cause mortality are reduced. ${ }^{8}$ Furthermore, CCBs may have better efficacy for preventing stroke than other classes of antihypertensive agents $;^{7}$ however, the degree of blood pressure reduction appears to be an important determinant of the size of this treatment effect. ${ }^{8-10}$ The efficacy of amlodipine for the treatment of hypertension in both normal- and high-cardiovascularrisk hypertensive patients has been demonstrated in multiple large clinical trials, ${ }^{5,11}$ and CCBs are included in various clinical guidelines as first-line recommendations for hypertension. ${ }^{1,12-14}$

In the Asia-Pacific region, hypertension may contribute to up to $66 \%$ of cardiovascular diseases. ${ }^{15}$ Research has demonstrated a linear relationship between blood pressure and stroke, and furthermore that the association between blood pressure and stroke
Correspondence: Kazuomi Kario Division of Cardiovascular Medicine, School of Medicine, Jichi Medical University, 33 I I-I Yakushiji, Shimotsuke, Tochigi 329-0498, Japan

Email kkario@jichi.ac.jp 
is stronger in Asian than Caucasian patients. ${ }^{16,17}$ Although the efficacy and safety of amlodipine $10 \mathrm{mg}$ has been confirmed in multiple studies, ${ }^{18-21}$ the option of increasing the amlodipine dose from $5 \mathrm{mg}$ to $10 \mathrm{mg}$ in patients who may benefit from the higher dose has been met with reluctance among some practitioners, especially in Japan, possibly due to concern about adverse events (AEs) (eg, pedal edema) with the $10 \mathrm{mg}$ dose. ${ }^{22}$

The objective of this study was to quantify the additional blood pressure efficacy achieved when titrating hypertensive Asian patients from amlodipine $5 \mathrm{mg}$ to $10 \mathrm{mg}$ and to compare this with data from Western patients.

\section{Materials and methods Study design}

This was a post hoc, retrospective, pooled analysis. Data from two similarly designed Phase III/IV open-label studies (AML-NY-93-002 and A0531086 [Pfizer data on file]) investigating the safety and efficacy of amlodipine in Asian patients with mild or moderate hypertension were pooled and compared with data pooled from three Western studies (A0531004, A0531044, and A053R0510 [Pfizer data on file]). Eligible patients were male and female, age $\geq 18$ years with mild or moderate hypertension (diastolic blood pressure $[\mathrm{DBP}] \geq 95$ to $\leq 120 \mathrm{mmHg}$, systolic blood pressure [SBP] $>140$ to $<200 \mathrm{mmHg}$ ). The five studies included in this analysis enrolled patients that mirrored actual clinical practice. Namely, they were a mixture of treatment-naïve patients and others who were uncontrolled on prior antihypertensives. All patients remained on stable treatment throughout the study.

Patients received amlodipine at a dose of $5 \mathrm{mg}$ daily for 4-8 weeks, and were then allowed to titrate to $10 \mathrm{mg}$ daily as needed, for an additional 4-8 weeks of treatment. Primary efficacy end points were the change from baseline to final visit in sitting SBP and sitting DBP. Baseline was established prior to titration, ie, after patients had received amlodipine $5 \mathrm{mg}$ daily for 4-8 weeks. Safety end points included assessment of AEs.

\section{Assessments}

Efficacy analyses included all patients in the intent-to-treat population who were titrated from $5 \mathrm{mg}$ to $10 \mathrm{mg}$ and had both a baseline and follow-up blood pressure measurement. Safety was assessed by measurement of the frequency of treatment-emergent AEs (all-causality), treatmentemergent serious AEs (all-causality), and AEs resulting in withdrawal from treatment (all-causality). Safety analyses included all patients who were titrated from $5 \mathrm{mg}$ to $10 \mathrm{mg}$ amlodipine.

\section{Statistical analyses}

The last observation carried forward was used to impute the end of study blood pressures for those patients who withdrew early. Descriptive statistics were used for quantitative variables and frequency counts by category for qualitative variables. A single-sample $t$-test was used to test the null hypothesis of no mean change from baseline in blood pressure, along with corresponding 95\% confidence interval (CI).

\section{Results}

\section{Study population}

Of the 174 patients included in the Asian analysis, 69 (40\%) were from Japan, with the remaining patients distributed across the People's Republic of China, Hong Kong, Indonesia, South Korea, the Philippines, Taiwan, and Thailand. Just over half of the patients were male, and the mean age of patients was 55.9 years (Table 1). The baseline mean (standard error [SE]) SBP was 149.3 (1.28) $\mathrm{mmHg}$ and DBP was 93.0 (0.84) $\mathrm{mmHg}$. For the Western analysis, 206/383 (53.8\%) patients were male, the mean age was 59.6 years, and the baseline mean (SE) SBP was 151.4 (0.82) $\mathrm{mmHg}$ and DBP was 90.5 (0.48) $\mathrm{mmHg}$ (Table 1).

Of the 174 patients included in the Asian analysis, $100 \%$ were treated and included in the efficacy and safety analyses. A total of 159 (91.4\%) patients completed the study, and 15 (8.6\%) discontinued. Reasons for discontinuation included AEs $(n=9,5.2 \%)$; withdrawal of consent and other (both $\mathrm{n}=1,0.6 \%$ ). For comparison, in the Western studies, 353 of 385 (91.7\%) completed the study, and 32 of $385(8.3 \%)$ discontinued due to AEs $(24,6.2 \%)$, patient no longer willing to participate (four, $1.0 \%$ ), other, and protocol violation (both two, $0.5 \%$ ).

\section{Efficacy}

Titration of amlodipine from $5 \mathrm{mg}$ daily to $10 \mathrm{mg}$ daily resulted in a statistically significant decrease in blood pressure.

Table I Baseline characteristics of the pooled Asian and Western populations

\begin{tabular}{lll}
\hline Characteristic & Asian $(\mathbf{n}=\mathbf{l 7 4})$ & Western $(\mathbf{n}=\mathbf{3 8 5})$ \\
\hline Male, $\mathrm{n}(\%)$ & $96(55.2)$ & $206(53.8)$ \\
Age, mean, years (SD) & $55.9(10.82)$ & $59.6(10.9)$ \\
Weight, kg (SD) & $67.0(12.16)$ & $84.3(15.7)$ \\
BMI, $\mathrm{kg} / \mathrm{m}^{2}(\mathrm{SD})$ & $25.5(3.77)$ & $29.3(4.3)$ \\
\hline
\end{tabular}

Abbreviations: BMI, body mass index; SD, standard deviation. 
Amlodipine $10 \mathrm{mg}$ lowered SBP by $-13.3 \mathrm{mmHg}(95 \%$ $\mathrm{CI}-15.5$ to -11.0$)$ and DBP by $-9.2 \mathrm{mmHg}(95 \% \mathrm{CI}-10.6$ to -7.8$)$ at the final visit ( $P<0.0001$ for both) (Figure 1$)$. These results were similar to those of the pooled analysis of three Western studies (SBP $-11.5 \mathrm{mmHg}, 95 \% \mathrm{CI}-13.1$ to -10.0 ; DBP $-6.3 \mathrm{mmHg}, 95 \% \mathrm{CI}-7.1$ to -5.5 ; both $P<0.0001$; Figure 2).

\section{Safety}

A total of 65 of 174 (37.4\%) Asian patients experienced 142 AEs (Table 2), of which infections $14.9 \%$ (26), musculoskeletal 12.6\% (22), gastrointestinal 9.8\% (17), and general disorders $9.8 \%$ (17) were the most commonly reported postbaseline. Peripheral edema occurred in eleven of $174(6.3 \%)$ patients. Serious AEs were reported by four patients (one cardiac disorder, $0.6 \%$; three neoplasms, $1.7 \%$ ). Treatment was withdrawn from nine patients due to an AE. Of the AEs that led to treatment withdrawal, neoplasms $(n=3,1.7 \%)$, general disorders $(n=2,1.1 \%)$, and nervous system disorders $(n=2,1.1 \%)$ occurred in one or more patients; cardiac disorders, gastrointestinal disorders, infections and investigations, each occurred in one patient. None of the patients discontinued treatment due to peripheral edema.

For comparison, in the Western studies, 100 of 385 (26.0\%) patients experienced 174 AEs (Table 2). Peripheral edema occurred in 35 of 385 (9.1\%) patients. Serious AEs were reported by two patients (cardiac disorder, $n=1,0.3 \%$; infections and infestations, $\mathrm{n}=1,0.3 \%$; and nervous system disorders, $n=2,0.5 \%$ ). Treatment was withdrawn from 14 patients due to an AE. Of the AEs that led to treatment withdrawal, general disorders $(n=10,2.6 \%)$; musculoskeletal and connective tissue disorders $(n=3,0.8 \%)$; nervous system disorders $(n=3,0.8 \%)$; psychiatric disorders $(n=2,0.5 \%)$, respiratory, thoracic, and mediastinal $(n=2,0.5 \%)$, skin and subcutaneous tissue $(n=2,0.5 \%)$, and vascular disorders $(n=2$, $0.5 \%)$ occurred in two or more patients. Nine $(2.3 \%)$ patients discontinued treatment due to peripheral edema.

\section{Discussion}

Although the need for effective management of blood pressure is well understood, adherence to antihypertensive treatment and blood pressure control continues to be a challenging international health goal. ${ }^{23}$ In recent guidelines, eg, those

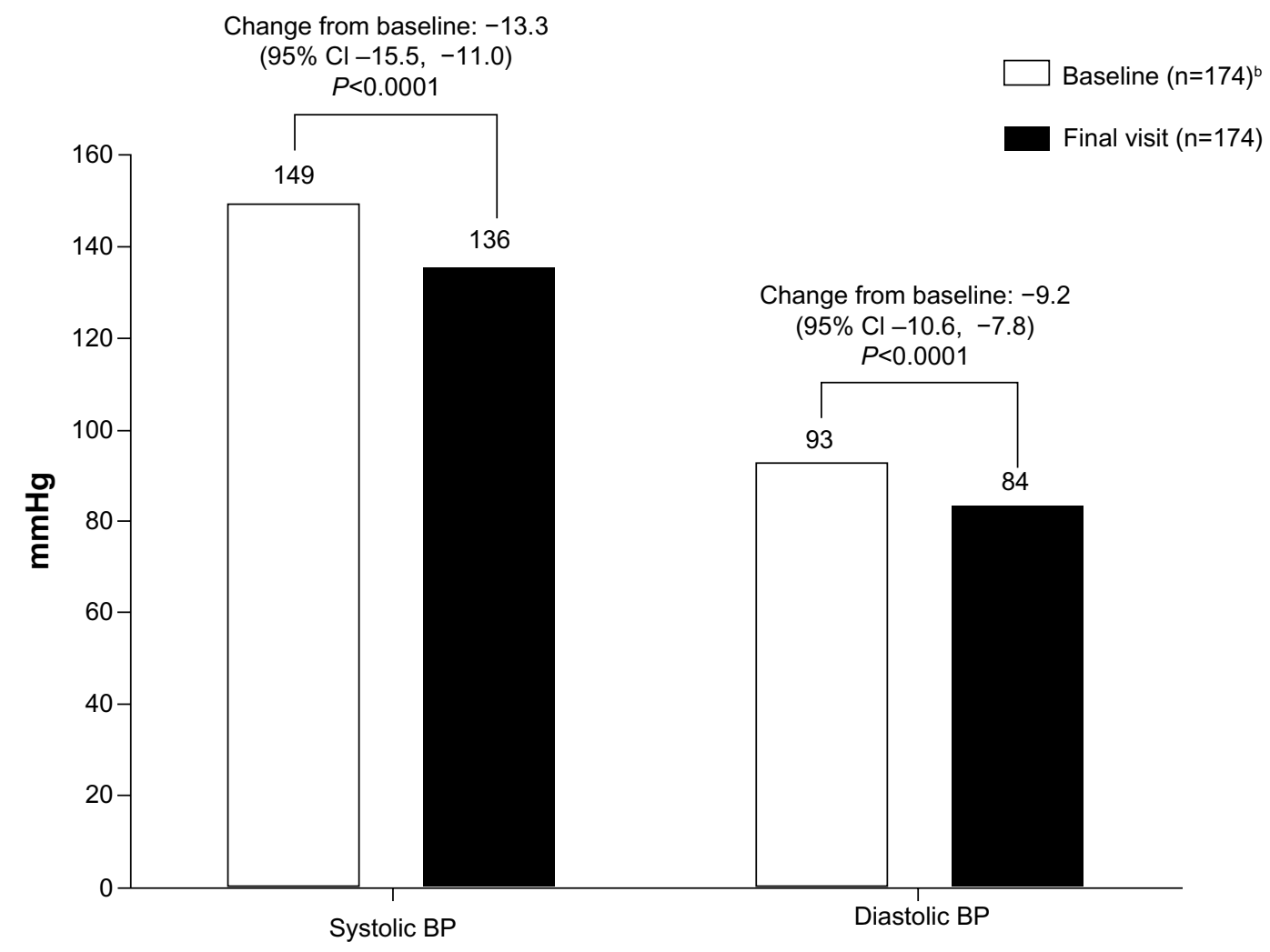

Figure I Blood pressure of patients titrated from amlodipine $5 \mathrm{mg}$ to $10 \mathrm{mg}$ from the pooled analysis of Asian studies, at baseline and final visit. ${ }^{\mathrm{a}}$

Notes: a Analyses conducted using the intent-to-treat population. $P$-values and corresponding confidence intervals $(\mathrm{Cls})$ were computed using a single-sample $t$-test; ${ }^{\text {b}} b a s e l i n e$ established while on amlodipine $5 \mathrm{mg}$.

Abbreviation: BP, blood pressure. 


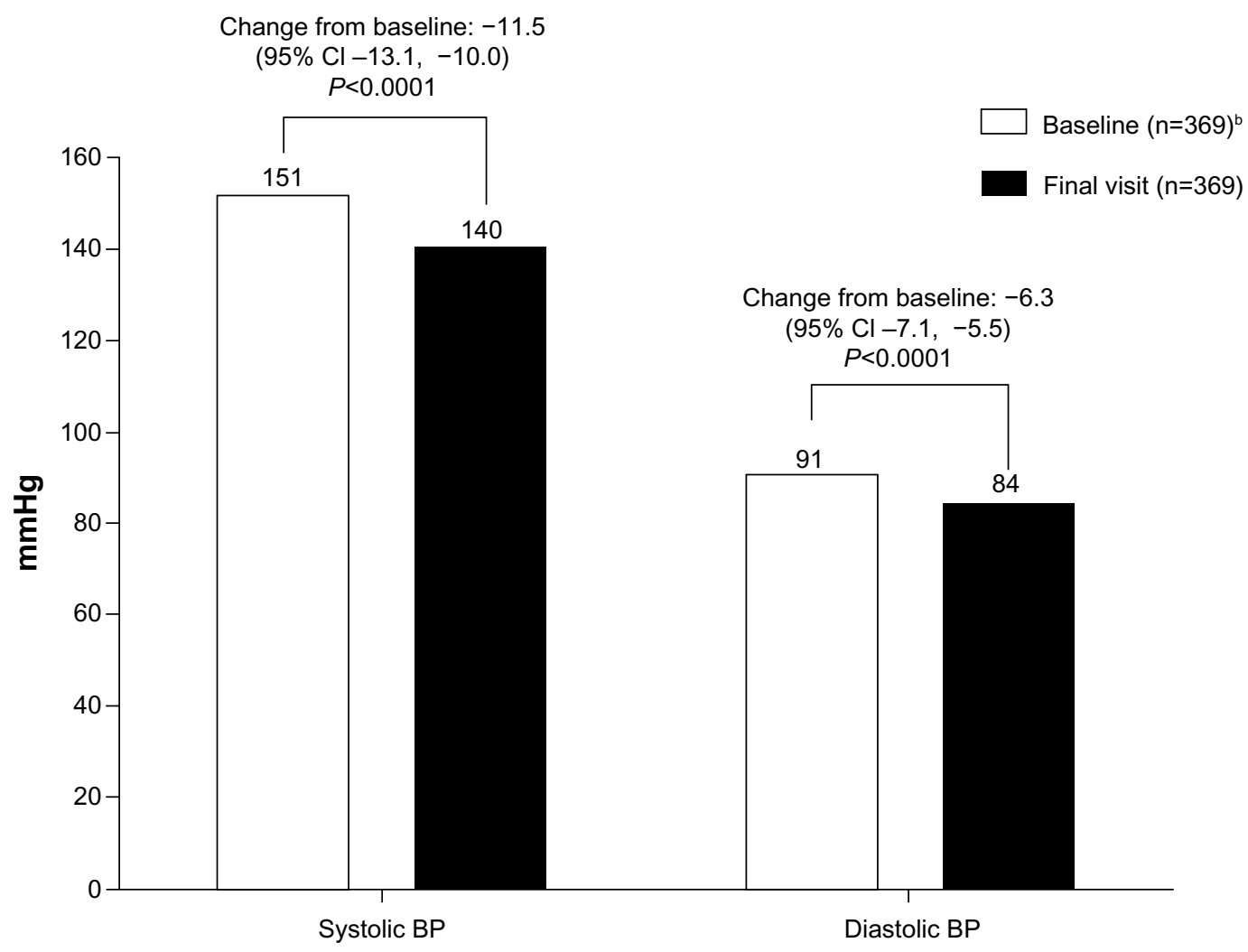

Figure 2 Blood pressure of patients titrated from amlodipine $5 \mathrm{mg}$ to $10 \mathrm{mg}$ from the pooled analysis of Western studies, at baseline and final visit. ${ }^{2}$

Notes: analyses conducted using the intent-to-treat population. $P$-values and corresponding confidence intervals (Cls) were computed using a single-sample $t$-test; ${ }^{\text {b baseline }}$ established while on amlodipine $5 \mathrm{mg}$.

Abbreviation: BP, blood pressure.

produced by the European Society of Hypertension/European Society of Cardiology, ${ }^{24} \mathrm{CCBs}$, such as amlodipine, are recommended as first-line antihypertensive agents.

The efficacy of amlodipine monotherapy in reducing blood pressure is well established in a number of populations, including patients aged $\geq 65$ years, ${ }^{25}$ pediatric patients, ${ }^{26}$ patients treated at primary and also specialized care centers, ${ }^{27}$ and patients of different ethnic origin. ${ }^{28}$ The results of a metaanalysis suggest that CCBs have better efficacy for preventing stroke than other classes of antihypertensive agents. ${ }^{7}$ Another meta-analysis determined that this benefit of CCBs extended to reduction in the risk for cardiovascular death, major cardiovascular events, and heart failure. ${ }^{8}$ For patients who receive amlodipine, the size of the reduction in risk of stroke is largely dependent on the magnitude of the reduction in blood pressure achieved. ${ }^{9}$ In particular, the association between blood pressure and stroke is known to be stronger in Asian than Caucasian patients. ${ }^{16,17}$ Furthermore, other research suggests that in addition to its antihypertensive-related effect, amlodipine has a blood pressure-independent beneficial effect on stroke risk; ${ }^{9}, 10$ administration of amlodipine may lead to enhanced endothelial nitric oxide production, inhibition of smooth-muscle cell proliferation, and antioxidant activity: effects not characteristic of some of the other CCBs. ${ }^{29,30}$ Recent evidence also suggests amlodipine lowers levels of highly sensitive cardiac troponin - which is associated with cardiovascular disease, mortality, and heart failure - to a greater extent than the combination of losartan and hydrochlorothiazide. ${ }^{31}$

Table 2 Incidence of adverse events for the pooled Asian and Western populations

\begin{tabular}{|c|c|c|}
\hline & Asian $(n=174)$ & Western $(n=385)$ \\
\hline Number of $A E s$ & 142 & 174 \\
\hline Patients with AEs, n (\%) & $65(37.4)$ & $100(26.0)$ \\
\hline Patients with SAEs, n (\%) & $4(2.3)$ & $2(0.5)$ \\
\hline $\begin{array}{l}\text { Patients discontinued study } \\
\text { due to } A E s, n(\%)\end{array}$ & $9(5.2)$ & $14(3.6)$ \\
\hline \multicolumn{3}{|c|}{ Most common all-cause AEs ( $\geq 2 \%$ of patients), ${ }^{a} \mathrm{n}(\%)$} \\
\hline Nasopharyngitis & $19(10.9)$ & $5(1.3)$ \\
\hline Edema, peripheral & II (6.3) & $35(9.1)$ \\
\hline Back pain & $8(4.6)$ & $2(0.5)$ \\
\hline Diabetes mellitus & $4(2.3)$ & 0 \\
\hline Flushing & $4(2.3)$ & 0 \\
\hline Oropharyngeal pain & $4(2.3)$ & $2(0.5)$ \\
\hline
\end{tabular}

Notes: aPooled Asian population. All patients were titrated from amlodipine $5 \mathrm{mg}$ to $10 \mathrm{mg}$ postbaseline.

Abbreviations: AEs, adverse events; SAEs, serious adverse events. 
There is a significant association between disrupted diurnal variations in blood pressure and cardiovascular disease. Nondippers with diminished nocturnal blood pressure fall, and risers with higher nocturnal blood pressure than daytime blood pressure are associated with target-organ damage and subsequent cardiovascular events. ${ }^{32,33}$ In addition, exaggerated morning surge is an independent predictor of cardiovascular events. ${ }^{34,35}$ Amlodipine maintains blood pressure in patients with diurnal variations in blood pressure, eg, it attenuates morning surge in blood pressure in hypertensive individuals. ${ }^{36}$ A once-daily dose of long-acting amlodipine can control ambulatory blood pressure throughout a 24-hour period in elderly uncomplicated hypertensive patients with different nighttime blood pressure dipping. ${ }^{37}$ The ALPHABET study demonstrated that the effects of high-dose $(10 \mathrm{mg})$ amlodipine on clinic, home, and ambulatory blood pressure control, and brain natriuretic peptide reduction were similar to the combination of losartan and hydrochlorothiazide. ${ }^{38}$ Furthermore, amlodipine may have additional protective benefits in not reducing nocturnal blood pressure to the extent that it accelerates brain ischemia in some hypertensive patients with marked nocturnal blood pressure reduction..$^{39,40}$

In this retrospective post hoc analysis, the titration of amlodipine from $5 \mathrm{mg}$ to $10 \mathrm{mg}$ daily significantly decreased both SBP and DBP in Asian patients with mildto-moderate hypertension. Amlodipine $10 \mathrm{mg}$ lowered SBP by $-13.3 \mathrm{mmHg}(95 \% \mathrm{CI}-15.5$ to -11.0$)$ and DBP by $-9.2 \mathrm{mmHg}(95 \% \mathrm{CI}-10.6$ to -7.8$)$ at the final visit $(P<0.0001$ for both). Not only were the results from this analysis similar to those of the pooled analysis of three Western studies, they also provide support for other studies that have also shown the benefits of titrating from amlodipine $5 \mathrm{mg}$ to $10 \mathrm{mg}$ in hypertensive Asian patients. In the Amlodipine Cohort Study by Internet-Based Research for Evaluation of Efficacy (ACHIEVE), Kario et $\mathrm{al}^{20}$ reported that in poorly controlled hypertensive Japanese patients, titration from amlodipine $5 \mathrm{mg}$ to $10 \mathrm{mg}$ daily significantly reduced both home and clinic blood pressure. Furthermore, these reductions seemed to be more pronounced among patients with higher baseline blood pressure than in those with lower baseline blood pressure values. In another study, Uno et $\mathrm{al}^{21}$ compared the efficacy and tolerability of amlodipine $5 \mathrm{mg}$ and $10 \mathrm{mg}$ in Japanese hypertensive patients, and found that amlodipine $10 \mathrm{mg}$ resulted in greater reductions in blood pressure versus amlodipine $5 \mathrm{mg}$. These blood pressure reductions were also shown to be significantly correlated with reductions in both hypertensive cardiac overload and renal damage (measured by brain natriuretic peptide and microalbuminuria levels, respectively). The wealth of studies reporting not only the dangers of sustained hypertension on the risk of cardiovascular events but also the benefits of uptitration to amlodipine $10 \mathrm{mg}$ in reducing elevated blood pressure highlights the importance of encouraging this strategy in prescribing patterns.

Overall, more AEs were reported in the Asian population than in the Western population (37\% versus $26 \%$ ). In particular, AEs of nasopharyngitis, back pain, diabetes mellitus, and flushing were all four times more common in the Asian population versus the Western population. Whereas it is well documented that diabetes is more prevalent in Asian subjects, the reason for the higher incidences of nasopharyngitis, back pain, and flushing reported in Asian subjects in this analysis is unknown. A possible explanation for the higher incidence of nasopharyngitis observed in Asian versus Western patients is that it has been reported that the Asians are more susceptible to catching colds than those from any other region; ${ }^{41}$ however, literature to support this theory is currently limited, and further research is required.

It has been reported that some practitioners in Asia, particularly Japan, are reluctant to prescribe a higher dose of amlodipine, perhaps due to concerns about an increased incidence of pedal edema with the $10 \mathrm{mg}$ dose. ${ }^{22}$ Of the 174 patients included in this pooled analysis, peripheral edema occurred in eleven patients (6.3\%). Furthermore, there were no treatment discontinuations as a result of peripheral edema, demonstrating that despite concerns, the increased dose of amlodipine is not associated with a worsened safety signal.

In summary, in this retrospective post hoc analysis, the titration of amlodipine from $5 \mathrm{mg}$ to $10 \mathrm{mg}$ daily significantly decreased both SBP and DBP in Asian patients with mild-tomoderate hypertension. The findings of this analysis support the uptitration of amlodipine from $5 \mathrm{mg}$ to $10 \mathrm{mg}$ in order to reduce blood pressure in Asian patients with hypertension.

\section{Disclosure}

This analysis was funded by Pfizer Inc. Jeffery Robbins and Barrett W Jeffers are employees of Pfizer Inc. Kazuomi Kario reports no specific funding in relation to this research and has no conflicts of interest to disclose on this paper. Editorial support was provided by Helen Jones, $\mathrm{PhD}$, and Michelle Jenvey, $\mathrm{PhD}$, of Engage Scientific and funded by Pfizer Inc.

\section{References}

1. Chobanian AV, Bakris GL, Black HR, et al. Seventh report of the Joint National Committee on Prevention, Detection, Evaluation, and Treatment of High Blood Pressure. Hypertension. 2003;42(6):1206-1252. 
2. Vasan RS, Larson MG, Leip EP, et al. Impact of high-normal blood pressure on the risk of cardiovascular disease. N Engl J Med. 2001;345(18): 1291-1297.

3. Lewington S, Clarke R, Qizilbash N, Peto R, Collins R. Age-specific relevance of usual blood pressure to vascular mortality: a meta-analysis of individual data for one million adults in 61 prospective studies. Lancet. 2002;360(9349):1903-1913.

4. ALLHAT Officers and Coordinators for the ALLHAT Collaborative Research Group. Major outcomes in moderately hypercholesterolemic, hypertensive patients randomized to pravastatin vs usual care: the Antihypertensive and Lipid-Lowering Treatment to Prevent Heart Attack Trial (ALLHAT-LLT). JAMA. 2002;288(23):2998-3007.

5. Dahlöf B, Sever PS, Poulter NR, et al. Prevention of cardiovascular events with an antihypertensive regimen of amlodipine adding perindopril as required versus atenolol adding bendroflumethiazide as required, in the Anglo-Scandinavian Cardiac Outcomes Trial-Blood Pressure Lowering Arm (ASCOT-BPLA): a multicentre randomised controlled trial. Lancet. 2005;366(9489):895-906.

6. Ogihara T, Nakao K, Fukui T, et al. Effects of candesartan compared with amlodipine in hypertensive patients with high cardiovascular risks: candesartan antihypertensive survival evaluation in Japan trial. Hypertension. 2008;51(2):393-398.

7. Law MR, Morris JK, Wald NJ. Use of blood pressure lowering drugs in the prevention of cardiovascular disease: meta-analysis of 147 randomised trials in the context of expectations from prospective epidemiological studies. BMJ. 2009;338:b1665.

8. Costanzo P, Perrone-Filardi P, Petretta M, et al. Calcium channel blockers and cardiovascular outcomes: a meta-analysis of 175,634 patients. J Hypertens. 2009;27(6):1136-1151.

9. Takagi H, Umemoto T. Revisiting evidence of blood pressure-dependent and independent effects of amlodipine on the risk of stroke. $J$ Clin Hypertens (Greenwich). 2011;13(10):781-782.

10. Wang JG, Li Y, Franklin SS, Safar M. Prevention of stroke and myocardial infarction by amlodipine and angiotensin receptor blockers: a quantitative overview. Hypertension. 2007;50(1):181-188.

11. ALLHAT Officers and Coordinators for the ALLHAT Collaborative Research Group. Major outcomes in high-risk hypertensive patients randomized to angiotensin-converting enzyme inhibitor or calcium channel blocker vs diuretic: the Antihypertensive and Lipid-Lowering Treatment to Prevent Heart Attack Trial (ALLHAT). JAMA. 2002;288(23):2981-2997.

12. Daskalopoulou SS, Khan NA, Quinn RR, et al. The 2012 Canadian hypertension education program recommendations for the management of hypertension: blood pressure measurement, diagnosis, assessment of risk, and therapy. Can J Cardiol. 2012;28(3):270-287.

13. Mancia G, Laurent S, Agabiti-Rosei E, et al. Reappraisal of European guidelines on hypertension management: a European Society of Hypertension Task Force document. Blood Press. 2009;18(6): 308-347.

14. Wang JG, Kario K, Lau T, et al. Use of dihydropyridine calcium channel blockers in the management of hypertension in Eastern Asians: a scientific statement from the Asian Pacific Heart Association. Hypertens Res. 2011;34(4):423-430.

15. Martiniuk AL, Lee CM, Lawes CM, et al. Hypertension: its prevalence and population-attributable fraction for mortality from cardiovascular disease in the Asia-Pacific region. J Hypertens. 2007;25(1):73-79.

16. Lawes CM, Rodgers A, Bennett DA, et al. Blood pressure and cardiovascular disease in the Asia Pacific region. J Hypertens. 2003;21(4):707-716.

17. Perkovic V, Huxley R, Wu Y, Prabhakaran D, MacMahon S. The burden of blood pressure-related disease: a neglected priority for global health. Hypertension. 2007;50(6):991-997.

18. Fogari R, Mugellini A, Derosa G. Efficacy and tolerability of candesartan cilexetil/hydrochlorothiazide and amlodipine in patients with poorly controlled mild-to-moderate essential hypertension. JRAAS. 2007;8(3):139-144.
19. Nissen SE, Tuzcu EM, Libby P, et al. Effect of antihypertensive agents on cardiovascular events in patients with coronary disease and normal blood pressure: the CAMELOT study: a randomized controlled trial. JAMA. 2004;292(18):2217-2225.

20. Kario K, Odawara M, Kimura K, Node K. Nearly half of uncontrolled hypertensive patients could be controlled by high-dose titration of amlodipine in the clinical setting: the ACHIEVE study. Curr Hypertens Rev. 2011;7:102-110.

21. Uno H, Ishikawa J, Hoshide S, et al. Effects of strict blood pressure control by a long-acting calcium channel blocker on brain natriuretic peptide and urinary albumin excretion rate in Japanese hypertensive patients. Hypertens Res. 2008;31(5):887-896.

22. Weir MR. Incidence of pedal edema formation with dihydropyridine calcium channel blockers: issues and practical significance. J Clin Hypertens (Greenwich). 2003;5(5):330-335.

23. Chockalingam A, Campbell NR, Fodor JG. Worldwide epidemic of hypertension. Can J Cardiol. 2006;22(7):553-555.

24. Mancia G, Fagard R, Narkiewicz K, et al. 2013 ESH/ESC Guidelines for the management of arterial hypertension: the task force for the management of arterial hypertension of the European Society of Hypertension (ESH) and of the European Society of Cardiology (ESC). J Hypertens. 2013;31(7):1281-1357.

25. Langdon C. Treatment of hypertension in patients $\geq 65$ years of age: experience with amlodipine. Clin Ther. 2000;22(12): 1473-1482.

26. Tallian KB, Nahata MC, Turman MA, Mahan JD, Hayes JR, Mentser MI. Efficacy of amlodipine in pediatric patients with hypertension. Pediatr Nephrol. 1999;13(4):304-310.

27. Valcárcel Y, Jiménez R, Hernández V, Arístegui R, Gil A. Efficacy and safety of amlodipine: a comparative study of hypertensive patients treated at primary- and specialised-care centres. Clin Drug Investig. 2006;26(3):125-133.

28. Sowunmi A, Walker O, Salako LA. Amlodipine as monotherapy in hypertensive Africans: clinical efficacy and safety studies. Afr J Med Med Sci. 1996;25(3):213-216.

29. Jorgensen B, Simonsen S, Endresen K, et al. Restenosis and clinical outcome in patients treated with amlodipine after angioplasty: results from the Coronary Angioplasty Amlodipine Restenosis Study (CAPARES). J Am Coll Cardiol. 2000;35(3):592-599.

30. Mason RP. Mechanisms of plaque stabilization for the dihydropyridine calcium channel blocker amlodipine: review of the evidence. Atherosclerosis. 2002;165(2):191-199.

31. Hoshide S, Fukutomi M, Eguchi K, Watanabe T, Kabutoya T, Kario K. Change in high-sensitive cardiac troponin $\mathrm{T}$ on hypertensive treatment. Clin Exp Hypertens. 2013;35(1):40-44.

32. Kario K, Matsuo T, Kobayashi H, Imiya M, Matsuo M, Shimada K. Nocturnal fall of blood pressure and silent cerebrovascular damage in elderly hypertensive patients. Advanced silent cerebrovascular damage in extreme dippers. Hypertension. 1996;27(1):130-135.

33. Kario K, Pickering TG, Matsuo T, Hoshide S, Schwartz JE, Shimada K. Stroke prognosis and abnormal nocturnal blood pressure falls in older hypertensives. Hypertension. 2001;38(4):852-857.

34. Kario K, Pickering TG, Umeda Y, et al. Morning surge in blood pressure as a predictor of silent and clinical cerebrovascular disease in elderly hypertensives: a prospective study. Circulation. 2003;107(10): 1401-1406.

35. Kario K. Morning surge in blood pressure and cardiovascular risk: evidence and perspectives. Hypertension. 2010;56(5):765-773.

36. Ishimitsu T, Minami J, Kawano Y, Numabe A, Takishita S, Matsuoka H. Amlodipine, a long-acting calcium channel blocker, attenuates morning blood pressure rise in hypertensive patients. Clin Exp Pharmacol Physiol. 1999;26(7):500-504.

37. Eguchi K, Kario K, Shimada K. Effects of long-acting ACE inhibitor (temocapril) and long-acting Ca channel blocker (amlodipine) on 24-h ambulatory BP in elderly hypertensive patients. J Hum Hypertens. 2001;15(9):643-648. 
38. Fukutomi M, Hoshide S, Eguchi K, Watanabe T, Shimada K, Kario K. Differential effects of strict blood pressure lowering by losartan/hydrochlorothiazide combination therapy and high-dose amlodipine monotherapy on microalbuminuria: the ALPHABET study. J Am Soc Hypertens. 2012;6(1):73-82.

39. Ishikawa J, Hoshide S, Eguchi K, Ishikawa S, Shimada K, Kario K. Nighttime home blood pressure and the risk of hypertensive target organ damage. Hypertension. 2012;60(4):921-928.
40. Kario K, Shimada K. Differential effects of amlodipine on ambulatory blood pressure in elderly hypertensive patients with different nocturnal reductions in blood pressure. Am J Hypertens. 1997;10(3):261-268.

41. Nielsen. Headaches, colds and backache - most common health complaints: Nielsen Global Survey. 2007. Available from: http://nz.nielsen. com/news/OTC_Aug07.shtml. Accessed July 29, 2013.

\section{Publish your work in this journal}

Vascular Health and Risk Management is an international, peerreviewed journal of therapeutics and risk management, focusing on concise rapid reporting of clinical studies on the processes involved in the maintenance of vascular health; the monitoring, prevention and treatment of vascular disease and its sequelae; and the involvement of metabolic disorders, particularly diabetes. This journal is indexed on PubMed Central and MedLine. The manuscript management system is completely online and includes a very quick and fair peer-review system, which is all easy to use. Visit http://www.dovepress.com/ testimonials.php to read real quotes from published authors.

Submit your manuscript here: http://www.dovepress.com/vascular-health-and-risk-management-journal 